\title{
EL PERIODISMO LITERARIO EN MANUEL LEGUINECHE: EL CASO DE EL CAMINO MÁS CORTO
}

\author{
LITERARY JOURNALISM IN MANUEL LEGUINECHE: THE CASE OF \\ EL CAMINO MÁS CORTO
}

Santiago Molina Ruiz

Universidad Complutense de Madrid España

Mail de contacto: sanmolin@ucm.es

\author{
Álvaro López-Martín \\ Universidad de Málaga \\ España
}

Mail de contacto: alvarolopezmartin@uma.es

\begin{abstract}
Resumen: Manuel Leguineche es uno de los principales exponentes del Nuevo Periodismo en la literatura latina, además de uno de los reporteros referentes sobre conflictos geopolíticos y de viajes durante el último tercio del siglo XX. Sin embargo, su figura y su obra ha sido escasamente abordada desde el ámbito académico. El objetivo de este estudio estriba en identificar, a través de un análisis de contenido cualitativo, los rasgos definitorios de El camino más corto, lo que nos permitirá conocer la incidencia del New Journalism en la producción de este libro y ahondar en el fenómeno de la literaturización de los viajes. El empleo sostenido de recursos literarios, la minuciosidad de las descripciones y el estilo personal y creativo, entre otras características, confirman el encuadre de esta obra dentro de la corriente del Nuevo Periodismo. Asimismo, en este libro Leguineche adopta e inaugura para el periodismo español el concepto The Heming-way of life, lo que refuerza su condición como uno de los textos de no ficción más representativos de la literatura hispanohablante del siglo pasado.
\end{abstract}

Palabras clave: Manuel Leguineche, periodismo literario, Nuevo Periodismo; periodismo de viajes; no ficción.

\footnotetext{
Abstract: Manuel Leguineche is one of the main exponents of New Journalism in Latin literature, as well as one of the leading reporters on geopolitical and travel conflicts during the last third of the 2oth century. However, his figure and his work have barely been addressed by the scholar research. This work aims to identify, through a qualitative content analysis, the characteristic of El camino más corto, which will allow us to know the incidence of New Journalism in the production of this book and
} 
to delve into the phenomenon of Literature of travel. The use of literary resources, the meticulousness of the descriptions and the personal and creative style, among other characteristics, confirm the framing of this work in the New Journalism. In addition, in this book Leguineche adopts and inaugurates for Spanish journalism the concept The Heming-way of life, which reinforces its status as one of the most representative non-fiction texts in Spanish-speaking literature of the last century.

Keywords: Manuel Leguineche, Literary Journalism, New Journalism, Travel Journalism, Non fiction.

Recibido: 09/09/2020. Aceptado: 29/06/2021.

\section{Introducción}

Con la influencia literaria de periodistas, filósofos y escritores, Manuel Leguineche configuró un estilo propio y singular que marcaría la forma de hacer periodismo en España, convirtiéndose en uno de los escritores referentes de la literatura hispana durante el último tercio del siglo XX. Los viajes y las relaciones personales que fraguó en ellos son fundamentales para comprender la virtud de este periodista que siempre se fijó en las personas comunes para crear una narrativa literaria dentro del reporterismo y de los viajes, lo cual tanto impacto tuvo en su vida.

Haciendo uso de las técnicas narrativas de la literatura, y con una clara incidencia del New Journalism, hizo de su primer gran viaje un libro, El camino más corto, que se halla en un macrogénero que aúna la literatura, el periodismo y los viajes. Esta obra, además de su trascendencia en la producción de este autor español, marcó el camino para muchos periodistas y escritores dedicados al viaje como forma de vida. Toda una serie de motivos y conceptos que construyen una teoría del viajero en el que la belleza estilística y la veracidad y el rigor de los hechos son esenciales para la creación de este tipo de obra.

La relación de la Literatura con el Periodismo, desde un punto de vista teórico, podría radicar en el concepto de mímesis explicado en Poética de Aristóteles, en el punto en el que la literatura es una representación de la realidad y, por ello, la literatura tiene nexo común con el periodismo y, en este caso, con los viajes. El binomio Periodismo-Literatura se consolidó en la década de los sesenta y setenta del pasado siglo con el boom del Nuevo Periodismo, cuyo estilo y literaturización de los textos periodísticos supuso 
un punto de inflexión en el ejercicio profesional del periodismo.

En este sentido, Tom Wolfe, Truman Capote, Michael Herr o Gay Talese, entre otros, fueron los impulsores de un fenómeno que en poco tiempo se trasladó a los países de lengua hispana. Así, Leguineche (España), Vargas Llosa (Perú), Tomás Eloy Martínez y Martín Caparrós (Argentina), Octavio Paz (México), García Márquez y Salcedo Ramos (Colombia), Otero Silva y José Ignacio Cabrujas (Venezuela), Onetti (Uruguay) son algunos de los autores que desarrollaron este fenómeno en España y América Latina. No obstante, autores como Rotker (1992) y Basso (2019) ubican el nacimiento del New Journalism no en los Estados Unidos, sino en América Latina.

A pesar de la importancia del periodismo literario, no abundan los estudios que ahonden en él (Chillón, 1999; López, 2005; Cuartero, 2014; Benavides, 2015; Angulo, 2016; Benavides, 2016; Basso, 2019; Limia, 2019) y los existentes ponen el foco principalmente sobre lo referido a la redacción periodística. Menos aún, los trabajos de periodismo literario sobre temática viajera. Por su parte, hasta ahora, la ausencia de investigaciones sobre la obra de Leguineche -pese a su notable protagonismo en el ámbito periodístico y literario español- ha sido una constante con tan solo la excepción de Galindo (2014). Con el presente trabajo se pretende, por tanto, paliar, aunque sea de manera parcial, este vacío en la literatura científica.

\section{El periodismo literario y su imprecisa definición}

Si bien la Teoría de la Comunicación ha procurado diferenciar el ámbito literario del periodismo (Gutiérrez, 2009), históricamente la influencia de la Literatura en el ejercicio periodístico constituye uno de los rasgos definitorios del periodismo español, especialmente en aquellas modalidades textuales en las que la incidencia autoral es más que evidente, como la crónica o el reportaje interpretativo. De hecho, autores como Martínez Albertos (1991) y Gutiérrez (2005) consideran el periodismo una disciplina heredada o subsidiaria de la Literatura, que, unidas ambas, dan pie al periodismo literario.

Previo a la 'explosión' del New Journalism o Nuevo Periodismo en los años 60 del siglo XX, la génesis del periodismo literario en España se podría ubicar en el primer tercio del siglo XIX (Rodríguez y Angulo, 2010; 
Fernández, 2016). Claros ejemplos son los artículos de costumbres de Mariano José de Larra y Ramón de Mesonero Romanos, en los que el empleo de técnicas literarias es evidente. Asimismo, a finales de ese siglo, la decadencia social y política del país contrasta con el surgimiento de una literatura regeneracionista con autores realistas como, entre otros, Clarín, Pérez Galdós, Octavio Picón o Pardo Bazán, todos ellos firmas habituales en los periódicos de la época.

Pese a la convivencia del Periodismo y la Literatura desde hace casi dos siglos, la bibliografía científica existente sobre la materia no aporta una definición única y precisa sobre el concepto de periodismo literario. Vinculado con lo anterior, Navarro (2014: 368) apostilla que el estudio sobre esta materia solo puede acometerse desde una perspectiva histórica, "descomponiendo los cánones estéticos de cada una de las épocas". Para Gil (2003), la irrupción del New Journalism reabrió el debate sobre la distinción entre Periodismo y Literatura, al suponer este una ruptura con el precepto básico del periodismo informativo: informar objetivamente sobre un acontecimiento real. Desde entonces, autores como Hellmann (1981), Heyne (1987) o Chillón (1999) han abordado los rasgos fronterizos entre Literatura y Periodismo. Al respecto, León (2010: 119) matiza lo siguiente: "lo literario, que no la Literatura, puede impregnar lo periodístico para darle valor añadido a éste; y eso es el periodismo literario".

Con similar propósito de definir el periodismo literario, paralelamente existe una corriente de autores que plantean legitimar el literary journalism como un género del periodismo (Connery, 1992; Sims y Kramer, 1995; López y Gómez, 2010; Benavides, 2015). Rodríguez y Angulo (2010) presentan una visión maximalista y lo conciben como un macrogénero que, a su vez, agrupa a otras modalidades textuales. Mayor consenso se infiere al describir las características con las que deben contar las piezas periodísticas literarias, en las cuales se une el rigor del reporterismo y la calidad estética de la producción textual (Rodríguez y Angulo, 2010). En términos parecidos se expresó con anterioridad Berner (1986) a través de su idea conceptual de literary newswriting -propuesta con escaso recorrido y basada en las premisas del Nuevo Periodismo-, en la cual asumía el uso de cualquier técnica o recurso literario siempre que lo relatado fuese fiel a lo acontecido. Relacionado con ello, es preciso destacar los "mandamientos" elaborados por Sims y Kramer (1995) para el periodista literario. Todas las 
premisas se articulaban en torno al rigor: "no usar escenas compuestas, ni cronología inexacta, ni falsificación de la deriva o proporción discernible de los eventos, ni invención de citas ni atribución de pensamientos" (1995: 25).

Sin embargo, como alertan diversos autores (Gutiérrez, 2009; Cuartero, 2014; Fernández, 2016), el periodismo literario ocupa una posición marginal en el ejercicio profesional del periodismo en España. No así en América Latina, donde la existencia de una red de revistas que apoyan esta modalidad textual posibilita una mayor presencia del periodismo literario (Cuartero, 2014).

\section{El periodismo de viajes ante un escenario de expansión}

La narración de los viajes ha sido una constante en la literatura y, posteriormente, en el periodismo. El viaje ha llamado a muchas generaciones de seres humanos a buscar lo fantástico en una realidad lejana donde se perseguía lo exótico, lo diferente, lo lejano y lo ajeno -aunque no siempre-. Al respecto, Forneas (2004: 223) aborda el binomio viajes-literatura y justifica su interés afirmando que "todo viajero es un cronista en potencia y que la experiencia del viaje no se completa hasta que no se cuenta”. Sobre esa relación, esta misma autora explica que no concibe la Literatura sin el periodismo de viajes, los cuales suponen una disciplina indivisible. Martínez Albertos (1991: 359) también aborda este fenómeno, el cual define como una modalidad "más literaria que periodística, [...] un pretexto para la literatura de escritores más o menos consagrados”. Algunos casos concretos de la literaturización de los viajes y que apuntalan la afirmación de Martínez Albertos (1991) son, entre otros, las crónicas de Josep Pla en Viaje en autobús (1942) o Diario de un poeta recién casado (1916) de Juan Ramón Jiménez. Asimismo, obras más recientes como la que centra la atención de este estudio y la trilogía de Javier Reverte sobre África -El sueño de África: En busca de los mitos blancos del continente negro (1996), Vagabundo en África (1998) y Los caminos perdidos de África (2002)-.

Sin embargo, a pesar del arraigo y tradición del periodismo de viajes desde mediados del siglo XIX (Belenguer, 2002; Pirolli, 2014), hasta hace escasos años -y en menor medida, continúa actualmente- ha tenido una 
consideración de rama de especialización periodística menor por la academia y la propia profesión periodística (Hannusch, 2010; Pokazanyeva, 2013; Pirolli, 2016). Este desprestigio se ha podido deber principalmente a su estrecha vinculación con la industria turística, lo que ha hecho que con frecuencia estos contenidos hayan sido concebidos predominantemente con fines publicitarios y/o económicos, más que periodísticos o estéticos. Frente a esto, autores como Belenguer (2002) o Mercado (2010) ponen en valor la identidad de esta modalidad periodística en base a sus exigencias y particularidades.

Asimismo, el creciente interés del público y las posibilidades narrativas que ofrecen las nuevas tecnologías han constituido en la última década las principales causas que han fortalecido la posición del periodismo de viajes (Martínez, 2012; Palau y Lekant, 2017). Además de las opciones interactivas, hipertextuales y multimedia, lo digital también ha posibilitado innovar en la producción y distribución de los contenidos (Tejedor, 2008; Xiang y Gretzel, 2010; Ulanova, 2014). De esta forma, las ventajas de la web 2.o y las redes sociales han sido aprovechadas para la creación y difusión de experiencias viajeras de manera visual y atractiva para las audiencias, dando pie a que en la actualidad la temática viajera sea una de las que mayor interés suscitan en el ámbito periodístico (Palau y Lekant, 2017). Por variedad de géneros -se aborda desde diversas ópticas: informaciones, entrevistas, artículos de opinión, reportajes, editoriales, etc.-, concentración de contenidos y exigencias narrativas y metodológicas (Fernández, 2007) el periodismo de viajes es una de las ramas de especialización con mayor vigencia.

Rotativos de referencia españoles como El País, El Mundo, eldiario.es y El Confidencial y latinoamericanos como Clarín y La Nación (Argentina), El Universal (México), El Universo (Ecuador) cuentan en sus ediciones digitales con secciones propias dedicadas a esta temática. Además, en la última década el periodismo de viajes también ha experimentado una eclosión en internet con el surgimiento de cientos de blogs (Palau y Lekant, 2017). Esta expansión se ve reforzada por el factor sociológico, dada la cada vez mayor importancia que tienen estos contenidos en el suministro de información para la búsqueda y elección de los destinos por parte de los viajeros (Larrondo y Tejedor, 2010; Hanusch y Fürsich, 2014). 


\section{Objetivos}

El propósito fundamental de esta investigación estribaba en explorar una de las obras referentes de la literatura hispana: El camino más corto (publicado originalmente en 1979), de Manuel Leguineche. A su vez, esto debía permitir profundizar en la obra de este escritor y periodista vasco, así como en el fenómeno de la literaturización de los viajes.

En aras de una mayor concreción, se establecieron varios objetivos subsidiarios. En primer lugar, interesaba analizar los rasgos de producción y contenido de la obra (O1). Íntimamente vinculado con lo anterior está el objetivo de determinar si este libro se encuadra, en base a su contenido y forma, en la corriente del New Journalism (O2), cuya eclosión se produjo no mucho antes de la publicación de El camino más corto. En tercer lugar, animaba nuestra investigación el propósito de contribuir -en la medida que los hallazgos permitieran- al estudio sobre el periodismo literario y ahondar en la tradición del periodismo de viajes en la historia del periodismo español (O3).

\section{Método}

De acuerdo con estudios previos (Angulo, 2013; Angulo, 2016; Chávez, 2019), el análisis de contenido cualitativo se antoja el método de investigación más apropiado para este trabajo. Dado que se persigue diseccionar $E l$ camino más corto desde una perspectiva pragmática, la presente investigación exige un discurso de tono ensayístico. Para ello, el análisis se abordó desde un enfoque interdisciplinario, considerando conceptos del ejercicio periodístico y de la teoría literaria. La elección de esta técnica responde a su versatilidad y flexibilidad instrumental para el análisis del mensaje (Neuendorf, 2002; Igartua, 2006; Barredo, 2015). Asimismo, Izcara (2014) sostiene que el análisis cualitativo permite ahondar en el significado y presencia de las palabras o ideas que constituyen la obra. En términos similares se expresa Pérez (1994), quien considera que esta técnica favorece la obtención de resultados interpretativos y profundos más allá de las cuestiones léxico-gramaticales.

En cuanto al alcance, este trabajo es de carácter exploratorio y descrip- 
tivo, debido, por una parte, a la escasez de investigaciones sobre esta temática y sobre Manuel Leguineche y, por otra, al propósito de describir las características de nuestro objeto de estudio. Para alcanzar los objetivos planteados se puso el foco sobre una serie de variables referidas a la producción y contenido de la obra, a través de las cuales se atendieron cuestiones como los temas abordados, el estilo, la narrativa, la naturaleza de los textos, los protagonistas, el desarrollo, etc. Todas ellas se organizaron a través de los siguientes bloques: a) El viaje; b) El viajero; c) El conflicto; d) La documentación; e) La descripción; f) The Heming-way of life.

\section{Desarrollo}

\section{El viaje}

En El camino más corto, el motivo del viaje surge por la mera posibilidad de hacerlo, como bien explica en las primeras páginas del prólogo de la primera edición:

Yo tenía poco más de veinte años y toda la vida por delante cuando en el verano de 1964 mi amigo Willy Mettler me habló por primera vez de una vuelta al mundo en coche para batir el récord mundial de distancia, sin repeticiones, con tres periodistas norteamericanos y él mismo [...]. Estaba yo hasta más arriba del gorro de aquella atmósfera opresiva de la universidad y de las tediosas clases de filosofía y letras [...]. Era el momento de dejarlo todo. (Leguineche, 2016: 25).

La motivación, en este primer gran viaje, es un hastío de una sociedad en la que no se siente cómodo ni en la que tiene grandes lazos como explica en las páginas siguientes. En una época complicada para los estudiantes que deseaban acabar con el "sindicato fascista" de la universidad y que habían recibido las cargas de los "grises", la mejor solución era buscar y buscarse en los lugares lejanos. Por este mismo motivo, la cita que inicia el libro pertenece al Diario de viaje de un filósofo, de Hermann Keyserling, y que, además, es donde procede el título de la obra.

Se trata, además, de seguir la estela de grandes viajeros-escritores que influyen de forma directa en Leguineche; súmese, como resulta obvio, la 
influencia que el franquismo ejerció para dejar la España de la época en busca de libertades que no eran viables entonces. El viaje, por tanto, es un motivo en sí mismo, además de un concepto propio en la teoría viajera expuesta por Leguineche a través de su obra. Entre otros causantes -como los anteriores señalados- hay que incidir en que el viaje se constituye como una motivación por sí misma.

\section{El viajero}

En El camino más corto el viajero, desde dos puntos de vista, es esencial porque a través de él se estructura y se configura el viaje. Se sostiene que se da a dos niveles porque se diferencia con claridad la percepción personal de Leguineche con el mundo que lo rodea y la que percibe de la percepción de sus compañeros Al Podell, Harold Stevens, Willy Mettler y Woodrow Stans.

Cada uno de ellos tiene una visión particular del viaje, de los pueblos y de los conflictos que hay en el mundo en el momento en que están efectuando el viaje de la Trans World Expedition. En este primer gran viaje de Manuel Leguineche ya se aprecia la filosofía de enfrentarse a las trabas que dificultan la correcta evolución del viaje, ya que repercute en el viajero. Pese a que Leguineche era proclive a viajar en solitario, en el caso de esta obra, lo hace con los compañeros antemencionados y se lanza al viaje con escasos conocimientos útiles para emprenderlo. Esto se aprecia cuando afirma que no sabía cambiar una rueda de repuesto, "estar especializado en cocinar huevos fritos”, no tener conocimientos básicos de acampada ni de medicina, aunque se ve obligado a maquillar estos conocimientos para ser aceptado en la expedición (2016: 27).

De este modo, en esta obra se contempla la construcción de Leguineche como viajero, unido con las penalidades de presentes en lugares donde es difícil sobrevivir, sea por causas naturales o humanas. Además, este viaje fue lo que desencadenó que fuese el periodista español más conocido y prestigioso en la guerra de Vietnam.

El viajero se convierte en un motivo literario y real (no ficticio) al mismo tiempo. Aquél es un nexo entre dos mundos, el de su origen y el de tránsito: desde los aduaneros, los pedigüeños, vagabundos, personas comunes y ladrones; presentes en los capítulos 2: Algo huele a podrido en Fez, 3: Sobre un campo de minas, 7: Las doce plagas de Egipto, 14: Accidente, 18: 
Perdido en el Hindu Kush, 25: Espía, 29: Sonrisas y píldoras; entre otros.

Las interacciones del viajero con estas personas demuestran que no debe haber desprecio, porque es muy probable que no les quede más remedio que ganarse la vida de esa forma, pertenece a las injusticias diarias que suceden en el mundo. Por tanto, el rechazo a estas gentes está injustificado por parte del viajero, ya que conoce los problemas a los que se enfrenta cuando recorre el mundo como viajero en lugar de turista.

\section{El conflicto}

En esta obra del autor vizcaíno el primer conflicto al que presta atención es la guerra entre Egipto e Israel, y se aprecia la tensa situación con la búsqueda de detalles que relacionasen a algunos de los medios de la expedición con la religión judía, una estancia previa en Israel o llevar algunos libros considerados subversivos.

Esto lo ejemplifica en el siguiente fragmento: "Entrar en Egipto en compañía de tres norteamericanos significaba, en 1965, desafiar la suerte. El chaparrón de preguntas que cayó sobre mis compañeros fue indescriptible. Los sabuesos de Nasser querían saberlo todo, casi, casi hasta el color de los calzoncillos del Jefe, Al y Wood" (Leguineche, 2016: 142).

En el capítulo en que esto sucede (7), en un momento ulterior afirma que la presión que ejercen los aduaneros era un "tormento" y los califica a los investigados como "víctimas", percibiendo, así, el ambiente cargado en el momento de las pesquisas para confirmar o denegar el acceso a Egipto.

Otro de los aspectos relacionados con la guerra y sus repercusiones son "el mercado negro y el contrabando" y la penuria ligada a ella. La situación era tal que explica que El Cairo buscaba productos procedentes del exterior y sofisticados, acordes con la época en que se encontraba como "transistores, cosméticos, cigarrillos americanos o té”. También asevera que había en aquel momento una "auténtica guerra entre policía, armados en sus jeeps, y las caravanas de camellos que atravesaban las pistas del desierto desde El Cairo" (Leguineche, 2016: 144).

El conflicto también se puede ligar a la oportunidad de contarlo, esto ocurre en el momento en el que Leguineche los aprovecha para vender noticias o reportajes a periódicos o agencias de información, llevando consigo la labor de los periodistas en las guerras. Así, ya se intuye la genealogía de 
la Tribu y los reporteros de guerra. Como en el antemencionado conflicto entre Paquistán e India, Tíbet y China, Egipto e Israel o la de Vietnam.

Entre la de India y Paquistán convirtió la vida en Nueva Delhi en una estancia "inaguantable" para Leguineche, a causa de las restricciones y la tensa atmósfera que se percibía en la ciudad y, como en Egipto, las acusaciones de espionaje llegan a un límite que roza con la demencia social. Este ambiente de denuncias a los extranjeros y personas "sospechosas" hizo que muchos extranjeros fueran detenidos sin ningún tipo de fundamento jurídico, entre los que se encontraban conocidos del autor.

Téngase en cuenta que la idea de conflicto en relación con el modo de vida del reportero le valió al autor quedarse como cronista de guerra en el sudeste asiático, impidiéndole concluir, en sentido estricto, el viaje que inició con sus compañeros.

\section{La documentación}

En la obra se manejan datos concretos sobre hechos acaecidos y del que no suele emitir juicios de valor, para que, así, el lector pueda generar su particular versión del asunto. Además de las explicaciones analépticas y prolépticas de vivencias personales como periodista, comenta sus consecuencias a un nivel general, por lo que favorece una visión inductiva y ligada con la narración.

En otros momentos, como en el capítulo 5: Siroco, a raíz de su travesía por Libia explica el ascenso al poder de Gadafi y el proceso de nacionalización de las empresas extranjeras situadas en el país norteafricano. Y también traza una semblanza del dictador, tanto de sus antecedentes como estudiante en el Reino Unido y la construcción de sí mismo por sus apariciones en televisión y uso de la imagen como propaganda, así como dictador de Libia.

A modo de ejemplo, cabe decir que en el capítulo 7: Las doce plagas de Egipto, en el que, entre otros hechos, narra el auge del mercado negro en Egipto a causa de la guerra contra Israel y del que había obtenido datos precisos sobre la cantidad de productos abandonados por los traficantes cuando los perseguían las autoridades. "Era frecuente encontrar en aquellas arenas cantidades industriales de los más variados productos abandonados por los contrabandistas. La última partida incluía 1.315 transistores, 
5.00o kilos de tabaco y 850 kilos de tejidos de lujo" (Leguineche, 2016: 145).

Con estos dos ejemplos se demuestran los dos tipos de documentación que maneja Leguineche, a saber, uno de índole histórico o historiográfico y otro periodístico, del que se infiere la obligación del reportero a investigar y aportar datos para corroborar lo que el periodista afirma y reforzar el discurso. Esto le proporciona al texto una dimensión de rigurosidad y veracidad que sustenta una visión periodística o de no ficción del texto y del discurso que plantea Manuel Leguineche.

\section{La descripción}

En las descripciones más literarias abundan las metáforas. Esta figura literaria posee una relación de los motivos entre las palabras comparadas y que tiene una relación entre los significados de las palabras conectadas en una comparación, a priori elíptica, aunque se traten de términos desemejantes.

Un ejemplo de ello se aprecia en la descripción que realiza del momento en el que los protagonistas se encuentran en la comisaría a causa de un atropello de coche: "En el suelo, bajo la luz de la lámpara de queroseno, yacía el cuerpo de un hombre con una navaja clavada en el estómago. Era una noche lorquiana de calor asfixiante y de tragedia gitana. Estaba tendido cuan largo era, con los brazos en cruz" (Leguineche, 2016: 142).

En estas líneas la luz y la metáfora cobran una importancia especial debido a la fuerte oscuridad imperante en las noches en Bagdad, así como las luces de queroseno que también aparecen en varias ocasiones. Otro aspecto muy recurrente en las metáforas de Leguineche es el calor, ya que las zonas que atravesaron en gran parte del viaje son lugares muy calurosos, como el norte de África, Oriente Próximo, el sudeste asiático o Australia. Por ejemplo, cuando escribe: "Bajo un sol homicida" (2016: 58).

En el ámbito del ser de los pueblos ofrece continuas reflexiones sobre los posibles motivos por los que son como son, sin olvidar las particularidades que siempre tienen componentes bellos. Un ejemplo de ello es la visión sobre los bereberes: "El hombre bereber es duro en el combate y astuto, como buen campesino, aunque sacrifique a veces su fortuna a la suntuosidad. Las mujeres, a las que vemos aquí sin velos ni tapujos. Llevan mantos 
con franjas de lana blanca y diademas de plata, perlas coral y monedas" (Leguineche, 2016: 54-55).

En el citado párrafo también se aprecia la referencia cultural, en este caso, a Federico García Lorca; pues asocia el navajazo que recibe un hombre con la obra de teatro del dramaturgo y poeta granadino. Así, establece una serie de relaciones entre la luz, la muerte, la cultura y los detalles -la propia forma del muerto-.

\section{The Heming-way of life}

El autor de El viejo y el mar con su primigenio trabajo de reportero de guerra inauguró un estilo que sería imitado tiempo después por muchos otros periodistas. Su estilo particular situaba al cronista de guerra en el peligro, su sello de identidad era la crudeza que vivía también como protagonista de la información que iba a contar. De este modo, el relato periodístico se introducía de forma muy clara a través de la vivencia personal de su narrador. Leguineche había acuñado este particular término para designar un modo de vida que funde peligro, viaje, vida y literatura y que es deudor de, al menos parcialmente, el reporterismo contemporáneo.

La afirmación es análoga a la tradición periodística que creó Hemingway, que podría estar tomada de los héroes clásicos griegos expresada a través de un héroe con características clásicas adaptadas a los hombres del siglo XX, en la que las luchas en las batallas se libran para, después, poder contarlo. Fermín Galindo asevera que los que llevan la Heming-way of life "disfrutan, como Enrique Carretero con el sonido de las balas, "la que me va matar no la voy a oír'. Y se disputan el título de la más puta entre las viejas zorras del oficio" (Galindo, 2014: 7).

La estética o poética del riesgo se ve representada en Hemingway por su visión sobre la tauromaquia, y en El camino más corto en la decisión de llevar a cabo un viaje sabiendo que en 34 países en los que pasarían había algún tipo de conflicto. El peligro y el riesgo se puede considerar en esta obra un aliciente para conseguir la hazaña de batir el récord del mundo en atravesar el mundo.

A modo de analogía con Ulises, el viajero debe saber por qué se marchó del lugar en el que vivía y cuál es su meta allí donde va, y para que se cierre el círculo que había comenzado tiene que buscar su regreso, tarde 
o temprano, como el héroe griego. Por ello, este héroe se convierte en el mejor de los ejemplos posibles, porque su última meta es el regreso a Ítaca $\mathrm{y}$, entretanto, necesita plasmar su personalidad para llegar a ser quien, en realidad, es.

Por los motivos ya mencionados, se estima que The Heming-way of life revive las actitudes -y busca las actitudes- de los héroes de antaño, viendo en el peligro y en los riesgos una suerte de poética que permite a quien lleva su vida de este modo adquirir un estatus superior de conocimiento sobre sí mismo y sobre el mundo que lo rodea, así como la predisposición a superar todos y cada uno de los obstáculos que se encuentra a lo largo del trayecto.

\section{Conclusiones}

El presente estudio ha permitido constatar la calidad y el rigor de El camino más corto, en cuyo libro su autor, Manuel Leguineche, refleja un estilo personal caracterizado por la influencia literaria. De este ámbito proceden numerosos recursos estilísticos -tales como metáforas, sinestesias, símiles, hipérboles o sinécdoques- que se emplean de manera sostenida durante toda la obra. Leguineche se sirve de muchas de estas figuras para realizar minuciosas descripciones de los entornos y personajes que aparecen, así como para la recreación de escenas y la reproducción de diálogos. Es, precisamente, a través de su figura - la del viajero-y, en menor medida, la de los distintos personajes que se registran, el eje en torno al que se articula la narración del viaje. Asimismo, si bien el escritor muestra una visión personal y particular sobre la naturaleza humana en momentos de conflicto en los que la tensión e histeria están muy presentes en las sociedades en guerras, este juicio de valor que se infiere de Leguineche no se manifiesta en el trato con las distintas personas que se cruzan en su camino, cuyos testimonios y relación no se ven alterados por posibles prejuicios del autor. Otra de las características que se evidencia en el análisis es el trabajo de campo y de documentación - previa y durante la travesía- realizada por el escritor vasco, quien se nutre de datos de carácter historiográfico y periodístico para una óptima comprensión del contexto. Esto dota a la obra de una mayor rigurosidad y veracidad, que se ve apuntalada por el uso de recursos testimoniales y documentales. En cuanto al espacio, destaca la variedad de 
escenarios y países de los cinco continentes registrados en la narración, centrándose predominantemente en África y Asia -con especial atención a Oriente Próximo y Extremo Oriente-. De esta forma, quedaría respondido el O1: notable incidencia del ámbito literario, empleo abundante de figuras estilísticas, minuciosidad en el relato, protagonismo del viajero como hilo argumental, multiplicidad de testimonios, manejo de un extenso repertorio de datos historiográficos y periodísticos e identificación de Asia y África como las principales áreas geográficas sobre las que pivota la narración.

Vinculado con el propósito anterior, el $\mathrm{O} 2$ estribaba en conocer si $E l$ camino más corto responde a las características formales del New Journalism. Algunos de los rasgos definitorios de este fenómeno son la reconstrucción fiel de los diálogos (Santibáñez, 1983; Sims, 1984), estilo personal en la redacción (Chillón, 1999; Cuartero, 2017; Limia, 2019), empleo de recursos expresivos o retóricos propios de la literatura para dotar al texto de una mayor riqueza de estilo (Connery, 1992; Chillón, 1999; Angulo, 2016; Cuartero, 2017), intención del escritor de ser participativo y creativo en relación con los sucesos que narra (Santibáñez, 1983), relata un hecho real (Connery, 1992; Weingarten, 2013), construcción de un marco narrativo atractivo para el lector, pero sin abandonar nunca el principio de la verdad (Sims y Kramer, 1995; Cuartero, 2014) y precisión en el suministro de datos e informaciones (Sims, 1984; Sims y Kramer, 1995; Cuartero, 2017; Limia, 2019). A tenor de las características recogidas y los hallazgos del análisis, podemos concluir que la obra objeto de estudio se engloba en esta corriente literaria/periodística iniciada en los años 60 del siglo XX. La literaturización del viaje, la precisión de las descripciones y el estilo personal y creativo -en el que se conjugan técnicas periodísticas y literarias- define la producción textual de El camino más corto, lo que evidencia la notable incidencia del Nuevo Periodismo en esta obra.

Por último, se perseguía ahondar en el estudio sobre el periodismo literario y el periodismo de viajes, así como en la figura de Manuel Leguineche (O3). En esta obra su autor hibrida la calidad literaria con el rigor periodístico, influido por la mencionada corriente. A ello habría que sumar la incidencia que ejerce sobre él la tradición literaria existente en el periodismo español desde el siglo XIX. Esto refuerza la condición de este libro como una de las obras de no ficción más representativas de la literatura hispanohablante. Asimismo, con El camino más corto el periodismo español 
adopta e inaugura el concepto The Heming-way of life, en el que se aprecia una belleza a las situaciones crudas vividas en la aventura y la relación que tienen con el yo. Una suerte de poética del peligro en la que la forma de vida del periodista sirve para el relato de los acontecimientos, llevando el concepto a una forma de vida. En lo que respecta al periodismo de viajes, constituye uno de los textos de referencia y con mayor relieve, debido a la diversidad de espacios relatados y la multiplicidad de testimonios autóctonos a los que se da cobertura. Esta práctica sostenida durante toda la trayectoria del escritor y periodista vizcaíno le posicionó como uno de los principales reporteros sobre conflictos geopolíticos y de viajes, además de ser uno de los mayores exponentes del Nuevo Periodismo en España durante el último tercio del siglo XX. El camino más corto ha repercutido directamente en periodistas y autores dedicados a la literatura de viajes y reporterismo de guerra, como Javier Reverte, para la creación de futuras obras.

Hasta ahora, la escasez de trabajos que aborden esta temática y la obra de Leguineche ha sido una constante, por lo que creemos que con el presente estudio contribuimos a paliar, aunque de manera parcial, este vacío en la literatura científica. No obstante, sería interesante continuar analizando en ulteriores estudios la producción de Manuel Leguineche, así como otros textos posteriores de la literatura hispana elaborados por reporteros de guerra o por autores enmarcados en la corriente del Nuevo Periodismo, lo que permitiría profundizar en la bibliografía y rasgos autorales de Leguineche y en su influencia en la literaturización de los viajes en el periodismo latino.

\section{Referencias}

Angulo, M. (2013). Crónicas de Buenos Aires. La megalópolis porteña en el periodismo literario argentino actual. Estudios sobre el Mensaje Periodístico, 19 (2): 615-633. doi: 10.5209/rev_ESMP.2013.v19.n2.43462 Angulo, M. (2016). El realismo intransigente del periodismo literario de Martín Caparrós. Compromiso político, sentido histórico y voluntad de estilo. Estudios sobre el Mensaje Periodístico, 22 (2): 627-645. doi: 10.5209/ESMP.54226

Barredo, D. (2015). El análisis de contenido. Una introducción a la cuanti- 
ficación de la realidad. Revista San Gregorio (1): 26-31. doi: 10.36097/ rsan.voio.113

Basso, C. (2019). La novela de Perón, Nuevo Periodismo y ficciones verdaderas. Acta Literaria (59): 93-106. Recuperado de: https://revistasacademicas.udec.cl/index.php/acta_literaria/article/view/1668

Belenguer, M. (2002). Periodismo de Viajes. Análisis de una especialización periodística. Sevilla, España: Comunicación Social.

Benavides, J. (2015). Origen, evolución y auge del periodismo literario latinoamericano: Desde las crónicas de Indias y el modernismo hasta las revistas especializadas. Questión, 1 (45): 36-44. Recuperado de: https://perio.unlp.edu.ar/ojs/index.php/question/article/view/2352

Benavides, J. (2016). ¿Literaturizar el periodismo o novelar la realidad? Una perspectiva a la hibridación disciplinaria y a la tradición del periodismo literario. Cognosis, 1 (1): 43-55. doi: 10.33936/cognosis.v1i1.231

Berner, T. (1986). Literary newswriting: the dead of oxymoron. Journalism Monographs. Columbia, Estados Unidos: The Association for Education in Journalism and Mass Communication.

Chávez, L. (2019). Compañeros de viaje: La meta(no) ficción como artificio de verosimilitud en historias sobre migración. Literatura y Lingüística, (40): 113-140. doi: 10.29344/0717621X.40.2063

Chillón, A. (1999). Literatura y Periodismo. Una tradición de relaciones promiscuas. Barcelona, España: Bellaterra, Universitat Autónoma de Barcelona.

Connery, T. B. (ed.) (1992). A Sourcebook of American Literary Journalism: Representative Writers in a Emerging Genre. Nueva York, Estados Unidos: Greenwood.

Cuartero, A. (2014). El arte del relato sin ficción: la explosión del Periodismo Literario en el ámbito latinoamericano y español en la Sociedad de la Información. Revista Surco Sur, 4 (7): 14-21. doi: 10.5038/2157$5231.4 \cdot 7 \cdot 7$

Cuartero, A. (2017). The concept of the New Journalism and its adaptation to narrative journalism in Spain. Doxa Comunicación (25): 43-62. Recuperado de: https://dialnet.unirioja.es/servlet/articulo?codigo $=6197711$

Fernández, A. (2016). El periodismo literario de Jame Campmany. Tesis inédita de Universidad de Murcia, Murcia, España.

Fernández, M. D. (2007). En torno al periodismo especializado. Consensos 
y disensos conceptuales. Anàlisi (35): 137-152. Recuperado de: https:// www.raco.cat/index.php/Analisi/article/view/74267

Forneas, M. C. (2004). ¿Periodismo o Literatura de Viajes?. Estudios sobre el Mensaje Periodístico (10): 221-240. Recuperado de: https://revistas. ucm.es/index.php/ESMP/article/view/ESMP0404110221A

Galindo, F. (2014). Manuel Leguineche, últimas noticias de nuestro enviado especial. Ámbitos (26): 1-20. Recuperado de: http://hdl.handle. net/11441/66634

Gil, J. C. (2003). Herencias literarias para un periodismo diferente. Razón y Palabra (31): 1-9. Recuperado de: http://hdl.handle.net/11441/17201 Gutiérrez, J. (2005). República, periodismo y literatura: La cuestión política en el periodismo literario durante la segunda república española. Madrid, España: Tecnos.

Gutiérrez, J. (2009). Acerca del periodismo literario. En Gutiérrez, J. (ed.) De Azorín a Umbral: Un siglo de periodismo literario español (pp. 2755). La Coruña, España: Netbiblo.

Hanusch, F. (2010). The dimensions of travel journalism: Exploring new fields for journalism research beyond the news. Journalism Studies, 11 (1), 68-82. doi: 10.1080/14616700903290569

Hanusch, F. y Fürsich, E. (2014). On the Relevance of Travel Journalism: An Introduction. En Hanusch, F. y Fürsich, E. (ed.) Travel Journalism: Exploring Production, Impact and Culture (pp. 1-17). Basingstoke, Reino Unido: Palgrave Macmillan.

Hellmann, J. (1981). Fables of Fact: The New Journalism as New Fiction. Illinois, Estados Unidos: University of Illinois Press.

Heyne, E. (1987). Toward a Theory of Literary Nonfiction. Modern Fiction Studies, 33 (3), 479-490.

Igartua, J. J. (2006). Métodos cuantitativos de investigación en comunicación. Barcelona, España: Bosch.

Izcara, S. P. (2014). Manual de investigación cualitativa. México D. F., México: Fontamara.

Larrondo, A. y Tejedor, S. (2010). Cuadernos de viaje 2.0: análisis de las oportunidades del weblog para el relato de viajes. Tercer Milenio (19). Recuperado de: http://www.periodismoucn.cl/tercermilenio/2010/ page/2/ 
León, T. (2010). La retórica del articulismo periodístico-literario. En Rodríguez, J. y Angulo, M. (ed.) Periodismo literario. Naturaleza, antecedentes, paradigmas y perspectivas (pp. 117-140). Madrid, España: Editorial Fragua.

Leguineche, M. (2016). El camino más corto. Barcelona, España: Ediciones B.

Limia, M. (2019). El periodismo literario de Ryszard Kapuscinski. Revista de la Asociación Española de Investigación de la Comunicación 5 (11): 246-267. doi: 10.24137/raeic.6.11.14

López, F. (2005). ¿Es posible el Periodismo literario? Una aproximación conceptual a partir de los estudios de Redacción Periodística en España en el período 1974-1990. Doxa Comunicación, (3): 11-31. Recuperado de: https://hdl.handle.net/10171/34903

López, F. y Gómez, B. (2010). El periodismo literario como sala de espera de la literatura. En Rodríguez, J. y Angulo, M. (ed.) Periodismo literario. Naturaleza, antecedentes, paradigmas y perspectivas (pp. 21-40). Madrid, España: Editorial Fragua.

Martínez Albertos, J. L. (1991). Curso general de Redacción Periodística. Madrid, España: Paraninfo Thomson Learning.

Martínez, V. (2012). Análisis de los portales de viajes de los periódicos españoles de referencia. Los casos de elviajero.com y ocholeguas.com. En Mateos, C. et al. (coord.), Actas IV Congreso Internacional Latina de Comunicación Social (pp. 1-20). Tenerife, España: Universidad de La Laguna.

Mercado, M. T. (2010). Aportaciones teóricas al concepto de periodismo especializado. Questión, 1 (28). Recuperado de: ttps://perio.unlp.edu. ar/ojs/index.php/question/article/view/1081

Navarro, D. (2014). Análisis histórico del periodismo literario de opinión español. En De Haro, M. V. (coord.) La Comunicación a través de la historia (pp. 361-383). Madrid, España: Visión Libros.

Neuendorf, K. (2002). A. The content analysis guidebook. Los Ángeles, Estados Unidos: Sage.

Palau, D. y Lekant, M. (2017). Periodismo de viajes e innovación en la red. Perfiles, apuesta y motivación de los bloggers. Zer, 22 (43): 167-184. doi: 10.1387/zer.17938 
Pérez, G. (1994). Investigación cualitativa. Retos e interrogantes. Madrid, España: La Muralla, S. A.

Pirolli, B. (2014). Travel Journalism in Flux: New Practices in the Blogosphere. En Hanusch, F. y Fürsich, E. (ed.) Travel Journalism: Exploring Production, Impact and Culture (pp. 83-98). Basingstoke, Reino Unido: Palgrave Macmillan.

Pirolli, B. (2016). Travel Journalists and Professional Identity. Journalism Practice, 740-759. doi: 10.1080/17512786.2016.1193821

Pokazanyeva, I. (2013). Problem Field of Travel Journalism as a Phenomenon of Contemporary Media Environment. Mediascope. Recuperado de: http://www.mediascope.ru/node/1385

Rodríguez, J. y Angulo, M. (2010). Literatos y periodistas: el origen de un matrimonio de conveniencia. En Rodríguez, J. y Angulo, M. (ed.) Periodismo literario. Naturaleza, antecedentes, paradigmas y perspectivas (pp. 57-70). Madrid, España: Editorial Fragua.

Rotker, S. (1992). La invención de la crónica. México D.F., México: Fondo de Cultura Económica de México D.F.

Santibáñez, A. (1983). Periodismo interpretativo y Nuevo Periodismo. Comunicación y Medios, (3): 71-86. Recuperado de: https://comunicacionymedios.uchile.cl/index.php/RCM/article/view/14956/15377

Sims, N. (1984). The Literary Journalists: The New Art of Personal Reportage. Nueva York, Estados Unidos: Ballantine.

Sims, N. y Kramer, M. (ed.) (1995). Literary Journalism: A New Collection of the Best American Nonfiction. Nueva York, Estados Unidos: Ballantine.

Tejedor, S. (2008). La Web 2.o en los cibermedios americanos. Barcelona, España: Universidad Autónoma de Barcelona.

Ulanova, I. (2014). Periodismo en Internet. Guía práctica. Moscú, Rusia: Aspect Press.

Weingarten, M. (2013). La banda que escribía torcido. Una historia del nuevo periodismo. Madrid, España: Libros del K.O.

Xiang, Z. y Gretzel, U. (2010). Role of social media in online travel information search. Tourism management, 31 (2): 179-188. doi: 10.1016/j. tourman.2009.02.016 